\title{
POR QUEM CANTAM AS SEREIAS DE HOMERO E O PARADOXO SISTÊMICO DA DECISÃO
}

\author{
FOR WHOM HOMER'S MERMAIDS SING AND \\ SYSTEM'S PARADOX OF DECISION
}

Leonel Severo Rocha* Fernando Tonet ${ }^{* *}$

\begin{abstract}
Resumo: Toda decisão judicial sobre casos difíceis, passa por uma elevada construção interpretativa. Sob um olhar sistêmico, a operatividade do sistema jurídico só pode ser observada se mantida sua integridade, ou seja, por seus próprios códigos. Quando Ulisses busca uma solução para salvar sua vida e de seus grumetes, mantém a estrutura, porém, faz uma decisão através de uma dupla observação: decidir salvar a vida de todos, porém, buscando fundamentos distintos, enquanto uns perdem, momentaneamente, o sentido da audição; Ulisses decide escutar as sereias. A decisão corresponde aos complexos casos, onde mesmo sem o canto das sereias (norma), o caso deve ser resolvido. Nesse sentido, é analisado o acórdão da $7^{\mathrm{a}}$ Câmara Cível do TJRS, na Apelação $n^{\circ} 70005798004 / 2003$, onde foi discutida a partilha de bens e direitos sucessórios de um genro infiel. O paradoxo apresentado representa o grande santuário da teoria sistêmica e a necessidade de decisão dos Tribunais.
\end{abstract}

Palavras - chave: Decisão; Interpretação; Paradoxo; Sistemas.

\begin{abstract}
Every court decision on hard cases goes through a high interpretive construction. From a systemic perspective, the operability of the legal system can only be observed if maintained their integrity, i.e. their own codes. When Ulysses seeks a solution to save your life and his cabin-cleaning boys, he maintains the structure, however, decides by a double observation: deciding to save everyone's lives, however, looking for different reasoning basis, while some lose, briefly, their hearing; Ulysses decides to listen to the mermaids. The decision corresponds to the complex cases where even without the mermaid's singing (norm), the case should be solved. Therefore, the 7th Civil Chamber's decision in Appeal No. 70005798004/2003, where there has been discussed the sharing of inheritance and property rights of an unfaithful son-in-law, is analyzed. The presented paradox represents the great sanctuary of systems theory and the need for decisions from courts.
\end{abstract}

Keywords: Decision. Interpretation. Paradox. Systems.

\footnotetext{
* Doutorado pela Ecole des Hautes Etudes en Sciences Sociales de Paris (1989) e Pós-doutorado em Sociologia do Direito pela Universita degli Studi di Lecce. Atualmente é Professor Titular da Universidade do Vale do Rio dos Sinos e Coordenador Executivo do Programa de Pós-Graduação em Direito. E-mail: leonel@unisinos.br.

** Mestre em Direito pela Universidade Regional Integrada do Alto Uruguai e das Missões - URI (2012). Doutorando em Direito pela Universidade do Vale do Rio dos Sinos - Unisinos. Estágio de doutoramento sanduíche na Universidad Diego Portales - Chile (2017). Advogado. E-mail: fernando.tonet@hotmail.com.
} 


\section{INTRODUÇÃO}

O presente artigo trabalha em um viés sistêmico um dos principais problemas da justiça, a decisão judicial. Para tanto, utiliza-se de uma perspectiva epistemológica que busca constranger positivamente os tribunais e julgadores a (re)fazerem suas decisões de forma correta, preservando a integridade do direito e a evolução jurisdicional. Nesse ideário, optou-se por estabelecer como marco teórico e metodológico a teoria sistêmica autopoiética, pois ela oferece ferramentas necessárias para o desenvolvimento complexo das decisões judiciais dentro de um sistema jurídico coerente e reflexivo.

O método de abordagem será o sistêmico autopoiético, possibilitando a construção das decisões judiciais através da utilização correta das normas jurídicas nos hard cases ou paradoxais, pois muitas vezes, em casos de lacunas jurídicas ou decisões legalmente injustas, deve-se buscar uma estrutura principiológica que possibilite a derrotabilidade das regras aplicáveis, para se manter a estrutura do sistema jurídico, inclusive entre áreas, como é o caso analisado, em que a congruência panprocessual deve ser mantida.

Nessa forma, trilhamos caminhos possíveis para uma decisão judicial correta, ou a mais correta para o caso concreto, onde se possa caminhar como em um romance literário na construção de uma fundamentação judicial que possibilite a evolução do sistema jurídico com integridade e seriedade.

Homero narra, no canto XII da Odisséia (HOMERO, 2013, p. 205 - 211), que Ulisses de Ítaca, zarpa com seu navio, acompanhado de seus grumetes pelos sendeiros, para ilha das sereias. $\mathrm{O}$ canto das sereias enfeitiça os marinheiros que ali passam, fazendo com que os mesmos se joguem à água para se juntar a elas, sem nunca mais submergirem. Curioso é que Ulisses, conhecido por suas estratégias, decide ouvir o canto das sereias, decidindo de forma paradoxal, pois amolga o ouvido de seus grumetes com cera, e solicita que lhe amarrem ao mastro do navio, assim, poderia ouvir o canto sem se entregar.

Em sua decisão Ulisses, confiava que sua artimanha simples, regada a cera, correntes e mastro poderia salvar todos, porém, a única voz que ouviu foi a sua, segundo Kafka (2013, p. 501), as sereias ao verem a cera e as correntes, esqueceram os seus cantos, impondo algo ainda mais terrível - seus silêncio - nesse paradoxal R. Fac. Dir. UFG, v. 42, n. 1, 129-144, jan/abr. 2018 
Por quem cantam as sereias de Homero e o paradoxo sistêmico da decisão

processo homérico, uns decidem ouvir, outros decidem pelo silêncio, mas de fato: todos decidem.

\section{A DECISÃO NOS PARADOXOS FUNDAMENTAIS DO DIREITO}

No complexo conjunto que forma o sistema jurídico, muitos elementos fundamentais da decisão permaneceram obscuros, traduzimos essas emergências a partir de casos difíceis, ou, como preferimos, paradoxos do Direito.

Os novos processos civilizacionais, criados pelos múltiplos contextos sociais, necessitam de perspectivas epistemológicas que possibilitem uma real análise de seus quadros jurídicos, dentro das dobraduras reflexivas oriundas das saliências existentes na atual crise de fundamentação teórica.

Em face da complexidade contemporânea, a lei não pode prever todas as hipóteses de aplicação para todos os casos existentes, existe uma porosidade normativa, onde nem todos os casos podem ser contemplados, contexto que necessita cada vez mais da utilização de princípios para fechar interpretações, bem como de respostas coerentes com o ordenamento jurídico.

Assim, uma interpretação íntegra, deve ser pautada pela busca de um princípio de fundamento moralmente político e jurídico. Esse princípio deve ter capacidade de afastar a regra geral, trazendo à tona a derrotabilidade da norma, dentro de uma perspectiva de congruência panprocessual. Essa derrotabilidade normativa pode ser articulada na forma de uma interpretação literária, extremamente próxima da jurídica, como um romance em cadeia demonstrando que essa resposta é reflexo da integridade e da coerência do direito.

Tanto no processo penal, quanto no processo civil, as decisões têm se apresentado de forma equivocada, criando uma verdadeira crise no sistema jurídico. Em suma, os magistrados primeiramente julgam, para depois fundamentar suas decisões. Toda busca íntegra por uma resposta adequada ao ordenamento constitucional passa por uma séria análise do sistema jurídico, para a criação de uma decisão, assim, é necessário fundamentar as teses para depois decidir, e não ao contrário.

O direito obrigatoriamente convive com a decisão, a obrigação decisional (CLAM, 2006, p. 106), cria uma busca intensa por sentenças aceitáveis, o paradoxo da decisão que não se pode decidir é buscar uma solução aceitável. 
A obrigatoriedade da decisão se torna o cavalo de Tróia do sistema jurídico, pois mesmo sem os códigos apropriados, em face da debilidade metodológica contemporânea, onde as observações são reduzidas e a complexidade aumentada, os Tribunais têm de decidir. O paradoxo é o ponto cego do sistema, e só esse ponto cego torna possível a operação da observação (LUHMANN, 2002, p. 234), isso faz com que o direito se torne uma história sem fim, o sistema autopoiético, produz elementos para produzir mais elementos, em sua estrutura o sistema deve buscar as respostas para suas decisões.

O processo circular cria no sistema jurídico mecanismos adequados à solução dos conflitos, essa paradoxalidade autopoiética do sistema fica nítida em casos complexos que exigem uma interpretação avançada dos julgadores no que tange os hard cases, que são um problema antigo nos processos de diferenciação do sistema do direito.

\subsection{A indignidade e os benefícios da torpeza}

O caso analisado é uma ação julgada pela sétima câmara cível do Tribunal de Justiça do Estado do Rio Grande do Sul ${ }^{1}$. Trata-se de uma análise jurídica ao direito de meação no divórcio onde se verifica indignidade por parte do autor de um delito punido criminalmente. O processo teve início em 1997, onde regia o código civil de 1916, os fatos demonstraram que a apelante foi casada com o apelado, e que aquele assassinou seu pai por motivo torpe. Porém, após a condenação criminal, a mesma buscou divórcio, no qual o apelado requereu seu direito de meação.

Ocorre que todos os bens da apelante foram provenientes da herança deixada por seu pai. Assim, alega não ser justo que o seu ex-marido possa ter direitos de meação, se beneficiando dos seus atos criminais. Entretanto, o código civil de 1996, em seu artigo 1.595, trata apenas como infiéis no recebimento de herança, os herdeiros e não os cônjuges dos herdeiros, tal lacuna se verifica também no código civil de $2002 \mathrm{em}$ seu artigo 1.814, que também não previu tal exclusão por infidelidade.

O relator do caso, Desembargador Brasil Santos, se demonstrou um positivista lógico, aplicando exclusivamente a norma, sustentando que a exclusão legislativa corresponde exclusivamente ao herdeiro e não ao cônjuge-meeiro, pois embora o apelado seja autor do homicídio, não é herdeiro da vítima, não podendo se 
Por quem cantam as sereias de Homero e o paradoxo sistêmico da decisão

admitir analogicamente uma interpretação extensiva que restringisse o direito da meação.

Em seu voto, afirma que não há uma lei em específico que possa ser aplicada, assim, não existindo base legal, o direito do meeiro estaria garantido, pois haveria uma lacuna.

Nesse sentido é importante distinguir entre lacuna na lei e lacuna no direito, para Kelsen (STRECK, 1999, p. 83), quando se fala em lacunas no Direito, não é porque uma decisão seja logicamente impossível ante a falta de disposições aplicáveis, e sim, simplesmente, porque a decisão logicamente possível aparece ao órgão aplicador como inoportuna ou injusta. Onde se fala em lacuna há somente uma divergência do Direito positivo e do Direito considerado mais justo.

Já a lacuna da lei ou técnica, é considerada quando legislador omite na norma algo que deveria ter posto para que a mesma fosse aplicada tecnicamente, exemplo: uma assembleia, para estar em exercício, tem se ser convocada pelo seu presidente; mas, ao mesmo tempo, determina que ela deve eleger o seu presidente (KELSEN, 2000, p. 277).

No caso concreto poderia ser dito que existe uma lacuna no direito, por não haver previsão legal de norma jurídica aplicável, porém, Kelsen (2000, p. 273), refuta essa ideia, pois mesmo quando o direito não diz nada, ele está dizendo algo. Assim, devemos entender que se o legislador não criou a lei, não foi por esquecimento, mas porque não quis criar, ou seja, uma ordem jurídica negativa.

Em Kafka (2013, p. 502), quando trata do silêncio das sereias de Homero, o próprio silêncio diz mais que o canto, pois no canto todos podem ser seduzidos por uma visão autográfica, ou seja, não é necessário um intérprete para descrever o fato, já no silêncio a interpretação passa a ser alográfica, necessitando de uma interpretação aguçada. Quando a norma silencia sobre algum fato, ela está se posicionando hermeneuticamente, para que no paradoxo sistêmico da decisão surja algo novo, assim, quando as normas não dizem nada, elas estão dizendo algo, basta que o observado busque suas justificativas, fundamentações, para a aplicação jurídica.

Sendo a norma um ato de vontade que regula a decisão humana, seria impossível prever todas as decisões humanas em concreto, assim, Kelsen se apoia na decisão judicial que seria a continuação do direito, não o começo, pois o direito sempre estaria em processo de criação. Kelsen supera o positivismo exegético, mas abandona o principal problema do direito: a interpretação no nível de aplicação. Assim, ele 
ultrapassa a letra da lei, porém não responde como o julgador deve interpretar a aplicar a norma.

O Desembargador relator, não consegue ultrapassar a norma, muito menos fundamentar sua decisão em um nível de aplicação, sua decisão está incorreta, positiva e interpretativamente.

A presidente da câmara Desembargadora Berenice Dias, concorda com o relator que tal fato não foi vislumbrado pelo código civil de 1916, porém, no momento em que o legislador criou a figura do herdeiro infiel, mostrou o elevado teor moral da norma, criando uma repulsa mesmo que não positivada de benefício do infiel. A lei não permite que o herdeiro se beneficie do crime, pois bem, o apelado não é herdeiro, mas é ex-marido da herdeira e os bens provenientes da meação correspondem à herança recebida pela apelante. Utilizando seu "senso de justiça" a presidente da câmara votou pelo provimento da apelação.

A Desembargadora, juntamente com seu colega, o Desembargador Teixeira Giorgir, vão além da norma. Utilizam-se de parte do ordenamento jurídico, como a lei de introdução ao código civil, artigo $4^{\circ}$, e principalmente se seus próprios sensos de justiça, para que o meeiro infiel não receba a meação advinda de sua torpeza. Porém não há qualquer embasamento legal para sua aplicação, ao contrário, um grave perigo surge da utilização da consciência em prol da justiça, pois quem irá nos proteger da boa vontade dos bons?

As teses psicanalíticas (LAPLANCHE, 2001, p. 93) comprovam que a consciência só pode nos oferecer um processo lacunar dos processos psíquicos, pois somos incapazes de observar a maioria dos fatos ocorridos, para utilizar a consciência precisaríamos de uma teoria que determine sua função e lugar, o que não existe no momento.

A resposta para a Apelação n. ${ }^{0}$ 70005798004/2003, passa basicamente por uma construção sistêmica séria, que deve se preocupar com a integridade do ordenamento, bem como eleve grau de constrangimento epistemológico pelo qual os julgadores devem passar, para que não se diga qualquer coisa sobre qualquer coisa.

Embora a presidente tenha se utilizado de um fundamento básico de moralidade legal, acabou fundamentando conforme sua consciência, sem um embasamento epistemológico avançado ou uma derrotabilidade da norma, conceito positivado no artigo 1.595 do código civil de 1916. 
Por quem cantam as sereias de Homero e o paradoxo sistêmico da decisão

Embora, tenha chegado a uma decisão possivelmente justa, essa não foi fundamentada pelos julgadores, que poderiam ter explorado o ordenamento jurídico e decidido de forma coerente e integra, se pautando por elementos materiais que estão no próprio sistema jurídico e não em suas consciências.

O sistema jurídico é uno, embora, possa ser observado de diversas formas, toda decisão jurídica deve advir de seus próprios fundamentos, e não da consciência individual de cada julgador. Buscaremos demonstrar que o processo já havia sido julgado na esfera criminal, e partindo de um princípio jurídico nemo auditur propriam turpitudinem allegans, ou seja, que ninguém pode se beneficiar de sua própria torpeza, um condenado criminalmente não poderia ter bons frutos na área civil.

\subsection{Análise reflexiva da congruência panprocessual na esfera criminal}

Estuda-se no direito moderno o instituto da congruência panprocessual, ou seja, uma decisão condenatória na esfera criminal não poderia gerar benefícios na esfera civil, pois estaria rompendo com a adequação, integridade e harmonia entre o sistema jurídico. Assim, a sentença condenatória, deveria ter - através dos efeitos da condenação elencados no código penal, artigo 91, II, b - limitado os direitos em relação a meação advinda da área cível.

Segundo Zaffaroni (2015, p. 765), a sentença criminal é a manifestação da vontade estatal, extraída da própria legalidade, assim, seus efeitos são caudatários do ordenamento constitucional, garantidos pelo princípio da legalidade - a lei criminal é expressa quando sustenta que o produto do crime ou qualquer outro proveito auferido pelo agente na prática do ato criminoso deve ser perdido. Assim, não poderia o juízo cível conceder benefícios da meação ao criminoso, pois estaria rompendo com a integridade jurídica.

Os efeitos da condenação não são novos no ordenamento jurídico, nasceram na década de 40, juntamente com o código penal. Roberto Lyra (1942, p. 462), sustentava que qualquer bem que importe proveito, que haja sido auferido com o crime deve ser confiscado.

Nos mais distintos ordenamentos do mundo ocidental ${ }^{2}$, os efeitos da condenação proíbem o agente criminoso de auferir lucro com seus atos. Nesse sentido, utilizando-se de pressupostos básicos do ordenamento jurídico, poderia ser vencida a regra de que apenas o herdeiro é infiel, pois para lei criminal, infiel é todo criminoso punido pela força estatal. 
Ao tratar das causas legais de deserdação, Pontes de Miranda (1973, p. 267), sustenta que não se necessita nem de uma condenação criminal para haver a deserdação, ou seja, ao dizer isso, pode-se entender que havendo condenação criminal, independentemente de quem seja o autor, esse não pode auferir valores, essa também é a posição de Beviláqua (1975, p. 780).

Mesmo que para o código penal o autor criminal seja uma figura una, podese questionar se no direito civil entre a figura do herdeiro e descendente, não pode haver uma figura intermediária. Esse intermediário, mesmo não elencado pela legislação civil, pode ser o cônjuge infiel ao direito sucessório, pois suas ligações pessoais com herdeiro ou descendente, lhe incluiriam nos benefícios obtidos pela herança.

Toda resposta ao presente caso, pressupõe um pedestal de pressuposições do direito, em uma análise teórico-reflexiva, as decisões do direito, vem de seus próprios pressupostos, assim, em última análise, todas as fontes jurídicas estão no próprio sistema do direito. Assim, a validade do fundamento construído passa por uma mútua circularidade, onde "[...] a decisão exige a regra como seu pressuposto na mesma medida que esta exige aquela" (CLAM, 2006, p. 120), os paradoxos e limitações comunicativas surgem com a própria positivação do sistema jurídico, para que se possa oferecer uma garantia jurídica na decisão, o interprete necessita entrar na rede de circularidade reflexiva do interprete.

Todo paradoxo nasce da perplexidade da impossibilidade de se manter apegado a norma legal vaga, assim, a busca por uma teoria que trabalhe as nodosidades de forma a buscar um clareamento do objeto jurídico é o ponto crucial no presente caso.

\section{A TEXTURA JURÍdICA E SEU VAZIO PARADOXAL}

A textura jurídica analítica, tem se demonstrado um legítimo palimpsesto, no qual os alfarrábios jurídicos são escritos uns sobre outros, pouco falando sobre os novos processos sociais complexos advindos com a globalização. Nesse intento, a analítica se torna uma doutrina de carneiros, já denunciada por Bentham (1962, p. 322), onde decisões são feitas em cima de decisões, pouco criando, ou buscando criar no sistema jurídico.

Como na Odisséia, os julgadores do caso analisado limitaram suas observações para poder chegar a uma resposta, porém, quando o relator do caso, 
Por quem cantam as sereias de Homero e o paradoxo sistêmico da decisão

enclausura seus sentidos para não ouvir o canto da legislação, que mesmo sem dizer nada, diz muitas coisas, os outros dois julgadores, se amarraram como Ulisses aos seus sentidos, utilizando sua própria consciência para julgar, ignorando que o canto/silêncio das sereias. Essa debilidade metodológica, criou uma obstrução da observação sistêmica, por não buscar respostas adequadas dentro do próprio ordenamento.

Uma das revoluções proporcionadas pela teoria luhmanniana foi a possibilidade de serem estruturadas novas observações do sistema. Assim, tudo estaria contido dentro do sistema social, toda produção de sentido estaria ligada a uma forma de observação.

Com o advento de novos fenômenos sociais, estar-se-ia forçando a criação de novas formas de observações, o que não significaria que essas observações não existissem, mas que apenas não teriam sido vistas, já que não eram necessárias.

Os sistemas são necessariamente fechados em um processo de clausura operativa, necessitando das observações que ocorrem dentro do próprio sistema para evoluir cognitivamente.

Uma vez que as observações não têm nenhum contato com o entorno sistêmico, toda a observação dependeria do ponto em que se está sendo observado. Luhmann diz "[...] las observaciones sólo pueden actuar sobre las observaciones, sólo pueden transformar distinciones en otras distinciones" (2007, p. 66). Assim, o objetivo da observação seria unicamente processar informações que advêm do seu entorno.

Quanto maior for o conhecimento do sistema sobre si mesmo, maior será a possibilidade de observação, pois “[...] toda observación del entorno presupone la distinción (autorreferencia/heterorreferencia), que puede hacerse sólo en el mismo sistema" (LUHMANN, 2007, p. 66). Dessa forma, o sistema poderá apenas observar, pois os conhecimentos advindos da observação são diferentes dos que operam dentro de si.

Nesse sentido, o acesso aos sistemas se dá através de observações externas, de onde o observador pode compreender o que se passa dentro do sistema, fazendo uma diferenciação do próprio sistema em que atua. O sistema interno nunca está acabado em sua plenitude, pois é dinâmico. Partindo desse pressuposto, a observação é extremamente necessária como evolução sistêmica.

A teoria dos sistemas luhmanniano tenta responder, através das observações, dois pontos relevantes: o primeiro diz respeito à diferenciação do binômio 
sistema/meio, como seria possível tal distinção; a segunda corresponderia ao tipo de operação necessária para que o sistema se produza.

O primeiro ponto deve ser observado exclusivamente pelo fechamento operativo, pois é ele que diferencia o sistema do meio e identifica quais são os seus elementos essenciais, estruturais, capacitando a separação entre o observador e o observado. Assim, o sistema deve ser apto a distinguir a totalidade dos organismos que observam dos que estão sendo observados.

Já o segundo ponto corresponde à natural reprodução sistêmica, que proporciona uma recursividade, uma autorreferência e uma circularidade comunicativa endógena sistêmica. Quando todos esses elementos estiverem contidos no sistema, ele poderá ter condição de abertura e evolução, pois terá capacidade de distinguir entre sistema e meio.

Uma das principais características da observação é a aplicação do conteúdo observado. Assim, "[...] tudo aquilo que um observador descobre sobre o sistema, deve aplicar a si mesmo" (LUHMANN, 2009, p. 77), pois sua operatividade é apenas intrasitêmica. O observador não pode atuar dentro do sistema observado, já que “[...] o observador não é um sujeito situado fora do mundo dos objetos; ele é, ao contrário, um deles" (LUHMANN, 2009, p. 154). O observador pertence, assim, ao sistema.

Dessa forma, enfatiza Luhmann, que "[...] en el mundo real hay sistemas que son descritos por otros sistemas, lo cual produce contradicciones lógicas que no pueden resolverse" (LUHMANN, 1998, p. 55), pois um sistema não pode operar sobre outro sistemas, suas observações são estritamente autorreflexivas, não produzem heterorreflexividade no interior dos sistemas observados.

Assim, a observação e o observador devem ser considerados como sistemas, “[...] uma vez que a observação não é um ato único isolado, mas sempre se dá em um conjunto de conhecimentos, em uma espécie de memória, em uma limitação de perspectivas, com restrições de ligação em relação a outras operações de observação" (LUHMANN, 2009, p. 76). Essas limitações são dadas pelo próprio sistema, através de suas expectativas que nem sempre serão sanadas.

Nesse sentido, Luhmann diz que “[...] somente por meio da observação das regularidades externas é possível ter acesso às estruturas do sistema" (LUHMANN, 2009 , p. 66), pois todos operam em clausura operativa e abertura cognitiva, através das observações. 
Por quem cantam as sereias de Homero e o paradoxo sistêmico da decisão

Com o advento dos problemas complexos, ou até hipercomplexos trazidos pela pós-modernidade, necessita-se cada vez mais de novas formas de observação, sendo que essas não podem mais ser unitárias, mas devem ser plurais, analisando todos os sistemas e todos os problemas, buscando sempre respostas que possam contrapor as expectativas.

A teoria dos sistemas de Luhmann "[...] constitui um sistema de autoobservação, recursivo, circular, autopoiético" (LUHMANN, 2009, p. 79), dotado de uma dinâmica intelectual fascinante, pois possibilita abordagens aos problemas advindos com o aparecimento da pós-modernidade.

Nesse contexto, Marcelo Neves sustenta, em linhas luhmannianas, que “[...] nenhuma teoria pode ser completa" (NEVES, 2009b, p. 260), necessitando sempre de novas observações. $\mathrm{O}$ autor demonstra que a contribuição da teoria luhmanniana aponta principalmente para as necessidades da sociedade moderna, onde modelos teóricos simplistas não poderiam mais ser justificados na complexidade global.

Para Rocha, não existem mais formas de observações verdadeiras, tranquilas e seguras, pois "[...] a globalização vai nos forçar a um outro tipo de observação que antes nós não tínhamos" (ROCHA, inédito, p. 12), ou seja, esses elementos observáveis existiam, mas não eram vistos, pois não eram necessários.

Luhmann (1998, p. 69) também alerta para variações ou desordens de observação, pois pode ocorrer uma entropia na observação, onde o observador não consegue tirar nenhuma conclusão acerca desse ato.

Existe na sociedade contemporânea um plano inimaginável de comunicações que não podem ser observadas, a alta redundância da comunicação social cria limitações em seus ângulos de observação, pois na comunicação hipercomplexa, a observação se torna também complexa, criando impossibilidades, nesse sentido, Clam relata que na "esfera da comunicação social possível não é formalmente definível" (CLAM, 2006, p. 24), assim, utilizamos o método de exclusão comunicativa para poder criar cruzamentos cognitivos comunicacionais.

Todo sistema se autorreproduz constantemente, mas todo observador tem um ponto cego, um limite de visão, um limite de observação, "[...] o observador não pode ver em virtude da sua posição ou perspectiva de observação” (NEVES, 2009a, p. 298), levando à máxima luhmanniana de que [...] “eu vejo o que tu não vês" (NEVES, 2009b, p. 273), exigindo uma forma de interação sistêmica comunicativa como possibilidade de evolução social. 


\subsection{O paradoxo na geração de direitos}

O sistema jurídico autopoiético é aquele que já está sob proteção da própria codificação sistêmica, assim, o paradoxo do direito, está inerente a sua própria estrutura, para Tonet (2016, p. 115), o paradoxo seria uma condição performativa, subjetiva do próprio observador, assim, não existiria apenas um paradoxo, mas vários, cada paradoxo ao seu tempo, ao seu meio e modo de aplicação.

Nesse sentido, Clam (2006, p. 200 - 216) sustenta que o direito seria gerado a partir de seu próprio paradoxo, porém, quando pensamos (observamos) o paradoxo ele já existe. Quanto mais comunicação existe, mais autorreferente os sistemas tem de ser, mais necessidade de observação é exigida e mais paradoxos são criados.

$\mathrm{Na}$ atualidade o direito é exigido como sistema a dar respostas através dos Tribunais, para todos os casos, o mesmo tem de decidir (LUHMANN, 2002, p. 384) independentemente de ser fácil ou difícil, da decisão ser conservadora ou criativa, a validade jurídica da decisão final não reside em momento algum em haver um consenso seguro da sentença, mas que utilize a maior possibilidade de observação sistêmica possível, e não a consciência pessoal como no caso discutido.

Com a obrigatoriedade da decisão os Tribunais não podem ter um consenso, ao contrário, o Direito reduz a complexidade, mas se auto alimenta dela. As normas jurídicas existentes que pertencem ao sistema jurídico, incontestavelmente são vigentes, mas quando aplicadas por métodos dedutivos, ou na debilidade metodológica criada pelo "decido conforme minha consciência", não conduz a decisões sérias, segundo Luhmann (2016, p. 419), na prática os Tribunais apenas se limitam ao que é mais necessário para justificar suas decisões, buscam decisões aceitáveis, nada mais.

O direito deve ser apreendido e desenvolvido como uma ciência em si, de forma autopoiética, onde as respostas estejam em suas próprias operações, onde as tensões externas não o afetem, em que a argumentação seja puramente jurídica, em um hiperciclo de recursividade. Assim, o paradoxo da decisão jurídica obriga o sistema a buscar soluções para os casos dentro de sua jurisdição.

Importante salientar que nem a lei, nem os contratos, nem decretos, podem decidir, essa obrigação é apenas dos Tribunais, ou seja, somente a eles existe o manejo dos paradoxos do sistema, pois só os operadores do sistema podem ser capazes de observações de validade jurídica. 
Por quem cantam as sereias de Homero e o paradoxo sistêmico da decisão

O direito por ser pressuposto é um produto do passado, os Tribunais têm a obrigação de (re)construir esse passado aos olhos do presente, um Tribunal não se pode apegar a lei, como se fosse a única observação possível, isso seria o que Ost (2005, p. 109), denomina de "os mortos enterrarem os vivos", ou seja, os caminhos da justiça ainda fundamentados em grilhões medievais.

Ao contrário, é obrigação dos Tribunais a conexão entre o passado e o projeto futuro, isso é a complexidade, pois somente aos tribunais recai a tarefa de supervisionar a consistência das decisões judiciais. Sistemicamente é incabível pensar em decisões onde as fundamentações se baseiam em não existir uma normatividade específica, ou no sentimento pessoal dos julgadores.

Clam (2006, p. 68) conceitua o direito como um subsistema, cuja função é regular as expectativas voltadas à comunicação social. Como a sociedade contemporânea produz uma comunicação policontextural, o direito sente os reflexos através de novas contingências, essas são entendidas como as possibilidades de decisão apontadas, e que poderiam ser diferentes, porém, dentro das próprias observações sistêmicas operativas.

Uma decisão jurídica correta deve passar por uma autopoiése sistêmica, onde os paradoxos concretizadores e as contingências criadas pelas policontexturalidades comunicacionais, devem ser analisadas pelos Tribunais, ou seja, os observadores devem procurar dentro do próprio sistema jurídico a fundamentação e validade de suas decisões.

A primeira etapa da decisão deve passar pela observação dos paradoxos, lembrando que nunca existe apenas um paradoxo para cada observação, ou seja, o consenso não é desejado em um processo sério. Os paradoxos são os responsáveis pelo desfazimento da nodosidade judicial, pois ele sempre está a frente de si mesmo "quando pensamos o paradoxo ele já existe"; num segundo momento, a decisão deve ser verificada dentro do arcabouço jurídico existente e de suas contingências, respeitando sempre uma integridade sistêmica operacional; por fim, a aplicação da decisão deve ser tomada de modo que o sistema se (re)construa a cada etapa, assim o direito gera a si mesmo de forma autopoiética.

\section{CONSIDERAÇÕES FINAIS}


Os passos que trilham a finalização de um artigo são feitos de forma sucessiva. Cada etapa é progressiva e busca o aumento do diálogo. Portanto, esse não é o momento em que faremos a reflexão de todos os resultados já discutidos, mas é o espaço onde será possível fazer apontamentos e reflexões sobre as questões já analisadas e aventadas.

O trajeto do artigo em momento algum se mostra retilíneo, sua sinuosidade constante nos impõe um devotado ato reflexivo. A finalização de um diálogo torna-se um processo complexo, pois dialoga com as pretensões já apontadas no passado, buscando um liame intrínseco com o futuro das propostas críticas, advindas de uma autorreflexão.

É sabido que as interpretações são feitas pelos entes interpretativos e não meramente encontradas, só através da linguagem podemos reproduzir conhecimentos. Muitas vezes, os textos dizem muito mais do que seus autores gostariam de dizer, mas muito menos dos que os leitores gostariam que dissessem.

O sistema jurídico vive no entremeio desse paradoxo, pois tem uma vasta linguagem que diz muito pouco para seus intérpretes, às vezes quase nada, enquanto seus leitores esperam sempre mais.

Estamos certos que com uma leitura séria dos paradoxos processuais, uma visão ampla do sistema jurídico é possível se chegar a uma decisão correta ou a mais correta para o caso. Nos dias atuais as decisões não são interpretadas, mas opinadas pelos julgadores conforme suas consciências, sem uma fundamentação legal estruturada em teorias epistemológicas sérias. Importam-se conceitos e os carnavalizam ao bel prazer do intérprete, sem qualquer constrangimento epistemológico.

Assim, sustentamos que uma decisão coerente passa primeiramente pela utilização de uma teoria apta aos processos complexos gerados pela pós-modernidade. Segundo, que o intérprete tenha uma macro observação do sistema jurídico, social e político, para que possa decidir mantendo a integridade jurídica. Essa decisão necessariamente passa por uma (re)construção de toda história institucional do direito, pois nenhuma interpretação nasce de um ponto zero. Após analisar todas as possibilidades da utilização de regras e princípios, dos confrontos possíveis e de sua coerência constitucional, deve o julgador decidir com a norma que melhor corresponda a coerência constitucional do direito. 


\section{REFERÊNCIAS BIBLIOGRÁFICAS}

BENTHAM, Jeremy. The Works of Jeremy Bentham. Edited by J. Bowring. New York: Russell \& Russell, 1962.

BEVILÁQUA, Clovis. Código Civil dos Estados Unidos do Brasil. Vol. IV. Rio de Janeiro: Editora Rio, 1975.

CLAM, Jean. Questões fundamentais de uma teoria da sociedade: contingência, paradoxo, só-efetuação. São Leopoldo: Editora Unisinos, 2006.

HOMERO. Odisséia. Tradução: Trajano Vieira. São Paulo: Editora 34, 2013.

KAFKA, Franz. O Silêncio das Sereias. In. HOMERO. Odisséia. Tradução: Trajano Vieira. São Paulo: Editora 34, 2013.

KELSEN, Hans. Teoria Pura do Direito. Trad. João Batista Machado. São Paulo: Martins Fontes, 2000.

LAPLANCHE, Jean. Vocabulário de Psicanálise. $4^{\circ}$. ed. São Paulo: Martins Fontes, 2001.

LYRA, Roberto. Comentários ao Código Penal. Vol. II. Rio de Janeiro: Revista Forense, 1942

LUHMANN. Niklas. Sistemas Sociales: lineamentos para uma teoria geral. Barcelona: Antrhopos; México: Univesidad Iberoamericana; Bogotá: Pontifícia Universidad Javeriana, 1998.

LUHMANN. Niklas. El Derecho de La Sociedad. Traducción: Javier Torres Nafarrate. Ciudad de México: Universidad Iberoamericana, 2002.

LUHMANN, Niklas. La sociedad de La sociedad. Traducción: Javier Torres Nafarrate. Ciudad de México: edición Heder, 2007.

LUHMANN, Niklas Introdução à Teoria dos Sistemas. Tradução: Ana Cristina Arantes Nasser. Petrópolis: editora Vozes, 2009.

LUHMANN, Niklas. O Direito da Sociedade. São Paulo: Martins Fontes, 2016.

NEVES, Marcelo. Transconstitucionalismo. Editora WMF Martins Fontes. São Paulo, 2009a.

NEVES, Marcelo. Niklas Luhmann: eu vejo o que tu não vês. In: Pensamento Alemão no Século XX. Org. Jorge de Almeida e Wolfgang Bader. Volume 1. São Paulo: editora Cosac Naify, 2009b.

OSF. François. O Tempo do Direito. Tradução: Élcio Fernandes. Bauru: Edusc, 2005. 
PONTES DE MIRANDA, Francisco Cavalcanti. Tratado de Direito Privado TOMO LVIII, $3^{\circ}$. ed. Rio de Janeiro: Editor Borsoi, 1973.

STRECK, Lenio Luiz. Hermenêutica Jurídica e(m) crise. Porto Alegre: Livraria do Advogado, 1999.

TONET, Fernando. Reconfigurações do Constitucionalismo: modelos constitucionais sistêmicos na pós-modernidade. $2^{\circ}$. ed. Rio de Janeiro: Lumen Juris, 2016.

ZAFFARONI, Eugenio Raúl. PIERANGELI, José Henrique. Manual de Direito Penal Brasileiro. 11 . ed. São Paulo: Revista dos Tribunais, 2015.

Artigo recebido em 11 de novembro de 2016 e aceito em 03 de janeiro de 2017

\footnotetext{
${ }^{1}$ Apelação Cível número 70005798004/2003 - $7^{\circ}$ Câmara Cível - TJRS.

2 Tal posicionamento é tão cristalino nas legislações internacionais, que podemos mencionar: Código Penal Italiano, em seu artigo 185, onde todo crime obriga a restituição das coisas e perda dos benefícios auferidos; Código Penal Uruguaio, em seu artigo 104, todo delito que se traduza, direta ou indiretamente, por mal patrimonial, acarreta, como consequiência, responsabilidade civil; Código Penal Argentino, em seu artigo 29, $2^{\circ}$, a sentença penal condenatória poderá ordenar a restituição da coisa obtida pelo delito; Código Penal Peruano, em seu artigo 65, o Ministério Público promoverá a restituição da coisa; Código Penal Cubano, em seu artigo 110, todo fato sancionável acarreta a responsabilidade civil, por responsabilidade civil compreende: a restituição in integrum; Código Penal Dinamarquês, em seu artigo 77, diz que o criminoso não pode auferir bens com seu ato criminoso em prol de uma segurança pública. (LYRA, 1942, p. 450 a 459).
} 